\title{
A Vez em que a Burocracia Estava Escondida no Banheiro
}

\section{The Bureaucracy was Hidden in the Bathroom}

\author{
Greice Martins Gomes \\ Henrique Martins de Soares \\ Ney Roberto Vattimo Bruck
}

Elaborado com base em uma situação real o presente caso de ensino busca relacionar teoria com prática por meio da confrontação de situações que envolvem nossa vida diária nas mais variadas formas organizacionais às quais fazemos parte. Propondo um método de ensino-aprendizagem participativo, visa aproximar os(as) alunos(as) da realidade da área de estudos em Administração a partir de uma percepção crítica e reflexiva da/sobre a realidade. Para tanto, toma-se como mote o conceito de burocracia que, a partir de uma perspectiva weberiana, pode ser interpretado enquanto forma de controle e dominação. Tomando isso como norte, nossa sugestão é "atuar" sobre a burocracia, justamente, por meio de seu oposto. Isso significa ponderar que, diante da normatividade, do formalismo e da fixidez da burocracia a criatividade, surge aqui como um possível caminho de desvio em direção a construções coletivas e organizacionais mais voltadas a uma perspectiva de autonomia e emancipação dos sujeitos.

Palavras-chave: burocracia, dominação, Estudos Organizacionais, caso de ensino.

Based on a real situation, the present teaching case seeks to relate theory with practice by confronting situations that involve our daily life in the most varied organizational forms to which we belong. Proposing a participatory teaching-learning method, it aims to bring students closer to the reality of the area of study in Administration from a critical and reflective perception of / about reality. Therefore, the concept of bureaucracy is taken as a motto, which, from a Weberian perspective, can be interpreted as a form of control and domination. Taking this as a guideline, our suggestion is to "act" on the bureaucracy, precisely, through its opposite. This means pondering that, in the face of normativity, formalism and the fixation of bureaucracy, creativity appears here as a possible path of deviation towards collective and organizational constructions more focused on a perspective of subjects' autonomy and emancipation.

Keywords: bureaucracy, domination, Organizational Studies, teaching case.
Recebido em: 01/11/2020 Aprovado em: 26/01/2021

Greice Martins Gomes iD
greice.martins.gomes@gmail.com
Doutoranda em Administração -
Universidade Federal do Rio Grande
do Sul
Federal University of Rio Grande do Sul
Porto Alegre/RS - Brasil
Henrique Martins de Soares iD
henrique_m_soares@hotmail.com
Especialista em MBA Gestão Empresarial
- Unisinos
Specialist Business Management -
Unisinos
Porto Alegre/RS - Brasil
Ney Roberto Vattimo Bruck iD
neybruck@gmail.com
Doutor em Psicologia - Universidade
Federal de Pelotas
PhD in Psychology -Federal University
ofPelotas
Pelotas/RS - Brasil




\section{O Caso}

"Era início de tarde, sala lotada, oitava série, quase cinquenta alunos e alunas, todos naquela euforia típica da puberdade", disse-me ele, e continuou: "percebi que aquela menina no fundo não se sentava [...] enquanto preparava minhas coisas para iniciar a aula ela surgiu na minha frente e disse baixinho "professor, eu estou menstruada, não estou me sentindo bem, eu precisava muito ir ao banheiro e repetiu: muito mesmo", eu olhei para ela e disse o óbvio: claro!". O que parecia ser óbvio, evidente, incontestável, para esse professor, por certo, não era o que se via ali. Este é o breve início de uma história verídica, ocorrida em 2010, em uma escola particular de ensino fundamental e médio, localizada na zona metropolitana de Porto Alegre, e que traz como pano de fundo o dilema da burocracia. A burocracia trata-se de um termo que pode ser usado de diferentes formas. As vezes de modo pejorativo e ligado a algum processo que passa por muitos trâmites demorados, complexos, ou mesmo, ao contrário disso, como uma forma de administração racional e eficiente. De fato, ela é tudo isso, mas seja como for, envolve duas variáveis em sua essência: controle e dominação.

\section{O FUNCIONÁRIO-PROFESSOR}

No dia em que foi chamado para receber a notícia de que fora selecionado para dar aulas naquela escola, foi abordado no corredor e recebeu o seguinte conselho: "não bata de frente com a direção, você já é o terceiro professor de sociologia desde o final do ano passado e nós só estamos em julho". Soube ainda naquele dia que os alunos não gostavam da matéria, principalmente depois que uma reformulação curricular acabou retirando horários que eram da Educação Física para colocar sua disciplina no lugar. "Logo quando cheguei para lecionar - contou-me animado que "era a paixão da sua vida" - "havia um livro texto nacional que deveria ser utilizado para as aulas. "Era um livro daqueles cheios de cronologias, datas, com marcos históricos sobre as teorias, sabe?" [...] daqueles que não tinham nada a ver com as questões que estes jovens estavam interessados em tratar, era muito descolado da realidade de vida deles, de questões que the eram interessantes como o papel das instituições tal como a família o governo, questões relacionada ao consumo, a globalização, as tecnologias como o caso das fake news, sobre identidades e coi- 
sas do tipo". Docente há muitos anos, tinha larga experiência em sala de aula em instituições privadas, além de ter sido monitor de várias disciplinas na Universidade Federal do Rio Grande do Sul. Também já havia, até este momento, desempenhado funções estratégicas em instituições públicas e privadas tais como escolas, hospitais e empresas. Destacou que, ainda antes do mestrado, realizou um trabalho de vários anos com educação popular na periferia de Porto Alegre e que durante o doutorado atuou como consultor, no Rio de Janeiro, em uma empresa financiadora de pesquisas. No episódio ao qual nos referimos, havia acabado o doutorado e estava "naquela fase que você está tentando se (re)posicionar para dar aula, mas que, enfim, as vezes não é uma coisa imediata dentro da realidade brasileira...então voltar a lecionar em uma escola e não exatamente em uma universidade parecia interessante naquele momento, afinal, sempre gostei muito de estar entre os jovens, gosto das questões que eles trazem, gosto deste momento do desenvolvimento que estão vivenciando, acho-os interessantes, criativos, alegres e sempre achei também que tenho um papel a contribuir socialmente e que através do ensino isso se torna possível". Quantos aos seus colegas, disse que a maioria ministrava aulas lá e em outras instituições também privadas e, de modo geral, considerava que tinham uma posição mais "conservadora"; "eu achava que o professor de sociologia tinha uma contribuição para dar em toda a escola pela questão interdisciplinar que é inerente aos assuntos tratados [...] sobre esta situação da aluna que me pediu para ir ao banheiro, que tu me perguntastes, ela foi uma, mas tiveram outras, eles [seus colegas] não me apoiavam, quem me apoiava mesmo era a coordenadora pedagógica que me contratou, que gostou bastante de mim e que tinha uma concepção de ensino e aprendizagem mais parecida com a minha, mas ela ficou doente um tempo depois e se afastou da escola, foi ela que me disse para não bater de frente com a Direção naquele dia".

\section{A ORGANIZAÇÃO-ESCOLA}

Tratava-se de uma escola conhecida por ser "rica", nas suas palavras, e por ter uma estrutura que alta qualidade, "com ginásios, laboratório, uma ótima biblioteca, bar, lancheira e coisas do tipo" com mais de cinquenta anos de atuação no estado do Rio Grande do Sul. Pertencente a uma rede de ensino composta por 16 unidades estudantis, atua nos segmentos de educação infantil, ensino fundamental 
e ensino médio. Nesta escola, segundo dados da época, atuavam mais de uma centena de docentes e aproximadamente oitenta colaboradores administrativos. Fora contratado para dar aulas para a sétima, oitava e todos os anos do ensino médio. As salas normalmente cheias eram um desafio à parte, "as vezes entre o quadro e a primeira fila de classes, eu tinha menos de um metro de distância”. Esta escola "era, como é na maioria das 'particulares'... Nas privadas, tudo é muito organizado, o espaço físico, o prédio, o xerox, tudo funciona bem, tudo organizado. Haviam diferentes instâncias de orientação pedagógica, de supervisão; em cada andar tinha um auxiliar de disciplina, uma pessoa contratada para esta função, ele ficava ali para ver se os alunos estavam dentro de sala de aula, se o professor precisasse de alguma coisa, na parte de baixo havia um portão, sempre cadeado, qualquer pessoa para entrar ou sair tinha que passar pelo guarda e por dentro da escola, para entrar no prédio onde ficava as salas de aula, tinha um outro portão". Caso os alunos se atrasassem 10 minutos eles não poderiam mais entrar na sala de aula, a porta era fechada após o início das aulas e assim deveriam permanecer até seu término, mas tu tens que ver que esta era uma escola paga, não era barata, e por isso ela tem 'facilidades' para quem não cumpre a disciplina, por exemplo, o estudante que chegou atrasado vai ficar em uma sala especial, climatizada, ele é tratado com simpatia e tal [...], lembro ainda que cada aluno recebia uma caderneta, tudo que acontecia ia parar lá, ela tinha que ser levada para aula, alguns não levavam as vezes... os mais disciplinados sempre tinham, ali tudo era registrado, anotava-se recado para os pais, os dias de prova, os eventos, os comunicados da Direção".

\section{O EPISÓDIO DO BANHEIRO}

O episódio do banheiro não era esporádico. Todos os alunos precisavam pedir autorização. Ele, pai de uma adolescente e sensível a questões ligadas ao feminismo, movimento do qual sua filha participava ativamente, conta que "algo bateu dentro dele" naquela situação "aquela menina, tendo que pedir para ir ao banheiro, uma coisa tão essencial para qualquer ser humano, como se a organização/ escola me colocasse em um lugar tal que eu pudesse definir sobre ela, sobre suas necessidades, como se ela fosse incapaz de decidir sobre o que era importante para ela naquele momento, naquela situação”. Disse-me que naquele dia sentiu-se particularmente incomodado e pensou em como poderia endereçar esta situação 
junto a turma. $\mathrm{Na}$ aula seguinte, chegou, deixou suas coisas sobre a mesa e disse para a turma "de hoje em diante ninguém mais precisa pedir para ir ao banheiro, vocês podem levantar e simplesmente sair e ir ao banheiro e voltar ou, se sentirem-se mais confortáveis, podem dizer algo do tipo ‘com licença eu já volto', é da cabeça de cada um". Notou que a turma ficou inquieta, alguns acharam bom, outros acharam graça, alguns pareciam incrédulos, mas houve aqueles que se posicionaram contrários. Um destes alunos, levantou-se e disse; "mas, 'sôr', tem gente que pede para ir no banheiro e não vai, tem gente que vai fumar escondido, tem outros que querem dar rolê pelo pátio...". Foi no que disse à turma: "as vezes os adultos dizem que vão ao banheiro e não vão. As vezes estamos simplesmente entediados, queremos tomar um ar, fazer outra coisa que não aquilo. Cada um de vocês pode e terá que se responsabilizar pela sua decisão, pela sua ação e pelo que poderá a vir a acontecer com isso, eu confio que cada um de vocês é capaz de tomar esta decisão e se responsabilizar por ela". Segundo contou-me, nas semanas que se seguiram alguns alunos pediam licença e saiam e logo retornavam, com o tempo notou que os pedidos de ir ao banheiro, que eram recorrentes, diminuíram.

\section{O CLIMA FICOU PESADO}

Certo dia, em uma reunião na escola notou um "clima pesado na sala, uma certa tensão". Foi uma reunião que seguiu sem percalços até que no final a coordenadora se dirigiu a ele, em meio ao grupo, e disse que os alunos estavam querendo ir ao banheiro sem autorização e que "isso estava incomodando a aula dos outros professores e é contra as normas da escola, gostaria de pedir que o professor revogasse isso com a turma". Sua resposta à coordenadora foi: "nas minhas aulas eu pratico aquilo que eu ensino, conteúdos de responsabilidade social e, portanto, individual, são elementos importantes não apenas de serem ensinados, mas efetivamente colocados em prática. Eu agradeço a fala da coordenadora, mas não posso faze-lo, seria um paradoxo entre ensino e aprendizagem. Na minha disciplina seguiremos neste formato, entendo perfeitamente que os demais professores não queiram seguir deste modo e respeito esta decisão como sei que respeitarão a minha. Aproveito para comentar, que o número de pedidos de alunos para ir ao banheiro caiu muito em minhas aulas e sinto que quando o fazem, agora, é pelo motivo devido". Suas aulas continuaram seguindo com os alunos tendo a possibilidade de deci- 
dir sobre ir ou não ao banheiro. Comentou-me também sobre duas situações antes desta. Uma delas envolvendo o livro texto, adotado como obrigatório pela escola, sobre o qual informou a direção que que iria usar parcialmente visto que o mesmo não o entendia adequadamente à disciplina e que, além disso os alunos diziam que achavam o mesmo chato e que ele concordava. A segunda, sobre outra reunião que havia participado na qual seus colegas e a coordenação teciam críticas à indisciplina dos alunos, classificados como "impossíveis" nas palavras do grupo. Ele fez uma intervenção neste dia comentando que parte disso acontecia porque o número de alunos, quase cinquenta por sala, era, não a única, mas certamente uma forte razão para isso estar acontecendo. Ao que a coordenação trocou de assunto e que o tema das aulas superlotadas não chegou a ser levantado, nem mais discutido no grupo.

\section{AULA SOBRE BUROCRACIA}

Como estava trabalhando Max Weber com a turma, resolveu trazer a questão do banheiro como um ingrediente para sua aula. Começou projetando no quadro branco a seguinte imagem, conforme figura 1 a seguir:

Figura 1 A Mafalda e a 'sua' Burocracia

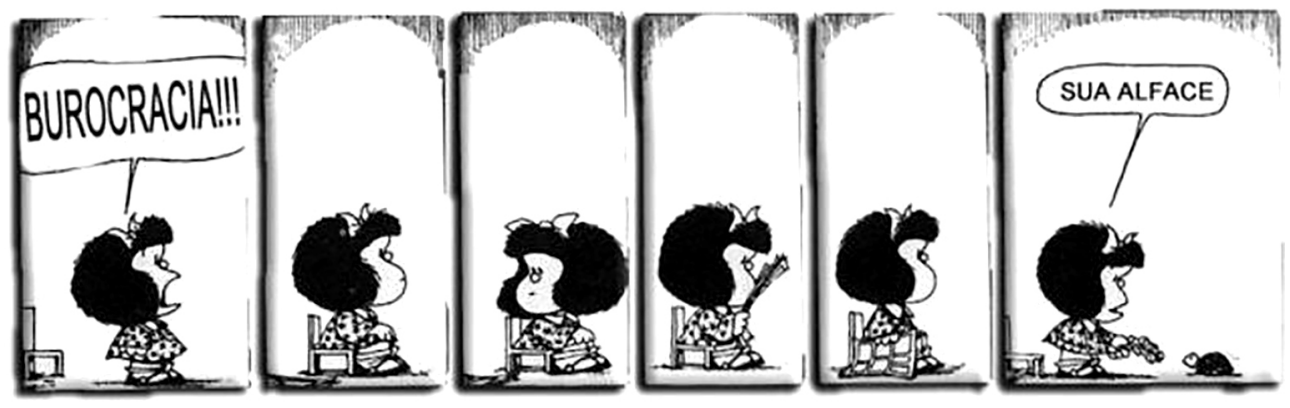

Fonte: Pinterest (2020)

"Para continuarmos nossa última aula sobre Max Weber, hoje eu trouxe este pequeno livro, eu já falei outro dia dessa coleção para vocês... ela se chama Primeiros Passos. A primeira edição deste aqui que se chama o 'O que é Burocracia'. Este livro, e vários outros desta mesma coleção, estão disponíveis gratuitamente pela internet, sugiro que deem uma olhada, tem vários assuntos interessantes... Ela 
se pretende breve e resumida, mas foi feita com ótimos autores convidados pela editora. Neste aqui o convidado foi o Fernando Prestes Motta que foi um professor da área da Administração, reconhecido como um dos importantes nomes no Brasil, sobre o tema da burocracia. E por que eu estou dizendo isso? Porque é preciso fazer este tipo de exercício, de ver quem é o autor, qual a importância dele, enfim, de 'onde' vem aquilo que vocês estão lendo. Mas, voltando ao nosso autor principal. Weber é conhecido, entre outras coisas, como um teórico das organizações. O bar aqui da escola, a loja que vende material de construção na esquina, a operadora do teu celular, o Facebook, o Google, mas também uma creche, um asilo, um quartel, um hospício, um hospital e claro, a nossa escola são todas organizações. Estou dizendo isso porque para autor que eu comentei [Fernando Prestes Motta] 'organização' é igual a burocracia. Isso significa dizer que em qualquer organização, em maior ou menor grau, haverá burocracia. Ela é aquilo que emerge como elemento mediador entre os interesses particulares e os interesses gerais, pois não podemos perder de vista que as organizações são produções humanas e não meros aparatos autonomizados. Sob esta ótica, ela refere-se não apenas a um sistema de organização formal, mas a um sistema de condutas. Ademais, burocracia é um termo que pode ser usado de várias formas, as vezes de modo ligado a algum processo que passa por muitos trâmites se tornando algo reconhecidamente lento como a "burocracia" aí da Mafalda. Em outras, é tido como uma forma de administrar considerada racional e eficiente. De fato, ela é tudo isso, mas para nossa discussão de hoje nos interessam, particularmente, dois aspectos que são inerentes a qualquer forma de burocracia e presentes em qualquer organização: o controle e a dominação. Para entendermos a burocracia temos que olhar para a história. Nas organizações pré-capitalistas a produção era artesanal feita por mestres artesão que detinham o controle da técnica e do conhecimento de produção das mercadorias (o sapateiro, o armeiro, o perfumista), assim como era ele que vendia diretamente o seu produto. O produtor controlava - tanto o produto quanto o processo de trabalho, não havendo, portanto, a separação entre capital e trabalho - característica fundamental do capitalismo (MOTTA, 2017). Assim, a divisão do trabalho surge, não exatamente pela superioridade técnica, mas porque desta forma a especialização das tarefas, a quebra disso em partes menores e desvinculadas do conhecimento como um todo, retira dos antigos artesãos (dos trabalhadores) o controle sobre o produto final e o 
coloca nas mãos de um único agente. Com isso o controle total do produto passou dos artesãos (da idade média) para o dono dos meios de produção. De modo que, é possível dizer que a burocracia é um sistema racional construído a partir da divisão do trabalho. Mas, de uma forma específica de organização da produção ela se expande, enquanto forma de relação social. Adentra a sociedade em geral através da ideia de controle, do predomínio do formalismo (velado ou não), na existência de normas escritas (em papel ou não), em estruturas hierarquizadas (sobre quem manda e quem obedece). O comportamento passa a ser disciplinado e caracterizado como errado/incorreto caso as 'normas' não sejam seguidas. Percorrendo por este caminho vamos nos deparar com a burocracia enquanto uma forma de poder e de dominação. Poder, porque se organiza de forma que alguns (poucos) podem impor sua vontade sobre (muitos) outros. Agora, quando esta imposição de vontade se torna aceita como válida, como coerente, certa, inquestionável por aqueles que são submetidos, aí então, o poder torna-se dominação - dentro de uma perspectiva weberiana. De modo geral, a burocracia é o oposto de autonomia, tanto individual quanto coletiva. Ela é capaz de criar costumes, normas informais, ideias e imaginários, tornando-se responsável, inclusive, por formas de controle intersubjetivo fazendo não apenas que sejamos controlados, mas que passemos a controlar os outros em prol desta estrutura formal. Ela limita uma gama de pensamentos e atitudes disponíveis ao indivíduo. O comportamento que as pessoas devem adotar (os/as alunos/as, os soldados, os empregados do Google, os idosos no asilo, as crianças na creche) são especificados e delimitados por sistemas de controle (gerencial) que - quando atendidos da forma esperada - podem outorgar gratificações e sistemas de recompensa (notas, soldo, salário/prêmios, mimos). Como vocês podem ver a burocracia não é uma coisa distante, ela está em quase todos os lugares; presente e atual ela é parte da nossa vida. Feitas estas considerações iniciais, eu gostaria de trazer o exemplo, de uma situação atual e que todos vivenciamos, para iniciarmos nossa reflexão sobre o tema, eu vou chamar est situação que vamos analisar e discutir nesta aula de "A vez em que a burocracia estava escondida no banheiro...".

\section{O DESFECHO}

Tudo isso ocorreu em um curto período. O professor estava em período de experiência durante os fatos aqui narrados. Disse que, estando para fechar os três 
meses, antes de ser efetivado, foi chamado a secretaria e demitido. Acha que fez o que devia, estava feliz com a experiência e acredita que se a coordenadora que o contratou, "aquela que ficou doente logo depois e se afastou da escola", estivesse lá, ele possivelmente não teria sido demitido. A entrevistadora pensa o contrário. Ficaremos os dois sem saber. Mesmo com os fatos narrados, que nos reportam sobre uma instituição com um histórico de demissões de professores de sociologia, não podemos deixar de considerar que existem consequências frente as decisões e posições tomadas no ambiente organizacional. Elas vão muito além das regras onde se pesam, para além delas, aspectos políticos, grupos informais e demais fatores desse tipo. Seja como for,contou-me que os alunos o procuram até hoje, pelas redes sociais recordando que achavam as aulas ótimas e que finalmente estavam gostando da matéria. Soube que um novo professor foi contratado, que o livro texto passou a ser novamente usado, que os alunos voltaram a se sentir entediados nas aulas. Mas uma coisa não foi mais a mesma, um tempo depois, por pressão dos alunos apoiados por um grupo de pais, foi instituído que os alunos poderiam ir ao banheiro, agora, sem ter que pedir por autorização. As sanções continuaram a ser aplicadas apara aqueles que "iam escondido no banheiro para fumar um cigarro ou apenas dar um rolê pela escola". Segundo teve notícias, essas situações também passaram a ser menos recorrentes. Este professor hoje leciona em uma importante instituição brasileira, sendo seu nome reconhecido, citado e requisitado dentro de sua área de atuação. Terminou sorridente e sereno a nossa entrevista citando o refrão de uma música que dizia: pé em deus e fé na taba". De nossa conversa/ entrevista ficou a mensagem que a burocracia não é 'boa ou má' em si, nem por si mesma. A disfunção ocorre quando existe opressão, cenários de arbitrariedade ou mesmo desrespeito empreendidos por meio e através dela.

\section{Notas de Ensino}

\section{FONTE DOS DADOS}

O presente material foi construído com fontes de origem primária, de modo que as informações apresentadas na narrativa são baseadas em uma situação real que se deu por meio de entrevista aberta, modelo usualmente utilizado para casos 
individuais (MINAYO, 2011). Em relação a sua estruturação, a entrevistadora introduziu o tema permitindo que o entrevistado tivesse a liberdade de discorrer sobre o mesmo; à medida que foram surgindo perguntas as mesmas foram respondidas dentro de uma conversação informal. Alguns ajustes no enredo, notadamente no que tange a subseção 'Uma aula sobre burocracia', foram feitos para fins de adequação ao modelo de caso de ensino e a proposta de discussão a qual se pretende instigar, contudo, tal adaptação foi informada e consentida pelo entrevistado. Tratando-se o presente material de uma situação-problema vivida por protagonistas reais optou-se por omitir os nomes dos participantes e da organização. Entende-se que tal ausência não interfere na interpretação do conteúdo ou mesmo na apreensão do dilema que permeia o caso.

\section{OBJETIVOS DE ENSINO E APRENDIZAGEM}

O caso tem como objetivo educacional desenvolver a capacidade de julgamento analítico e crítico, relacionar a teoria com a prática, confrontar as complexidades de situações específicas que envolvem nossa vida nas mais variadas formas organizacionais as quais fazemos parte, bem como tornar o processo de ensino mais dinâmico e criativo. Foi pensado como uma contribuição em nível de graduação e pós-graduação para as áreas de Estudos Organizacionais, Administração Geral e Pública, mas também as Ciências Sociais aplicadas e Humanas de um modo geral "dado que o fenômeno da burocracia está presente em todos os âmbitos sociais" (DE FARIA; MENEGHETTI, 2011). O presente trabalho oferece um método indutivo de ensino-aprendizagem de natureza participativa visando o envolvimento dos(as) alunos(as) no sentido de aproximá-los da realidade da área de estudos da Administração a partir de uma percepção crítica e reflexiva da/sobre a realidade.

\section{QUESTÕES PARA DISCUSSÃO}

1. Que situação the vêm à mente que poderia ser considerada uma forma da burocracia agindo sobre você, sobre sua liberdade de escolha, de participação, de ação? (pode ser também uma história sobre alguém, ou uma situação que tenha conhecimento) 
2. O que o pedido da aluna para ir ao banheiro tem a ver com burocracia? Que relação existe entre tal episódio e uma perspectiva organizacional?

3. "Ela [a burocracia] é capaz de criar costumes, normas informais, ideias e imaginários, tornando-se responsável inclusive por formas de controle intersubjetivo". Cite uma ou duas situações em que a dominação burocrática mostrou-se nos personagens como uma forma de controle intersubjetivo. Reflita com seu grupo por que, enquanto administradores, seria relevante dar-se conta sobre tais situações?

4. Quais seriam as possíveis 'saídas' que o grupo poderia propor para tal situação? 4.1) em busca de uma saída individual: que outra forma esta situação poderia ter sido endereçada pelo professor e que resultados você prevê que ele alcançaria? que outra forma esta situação poderia ter sido endereçada pela gestora da escola? e que resultados você prevê que ela alcançaria? 4.2) em busca de uma saída coletiva: que tipo de articulação coletiva poderia ter sido feita nesta situação e que resultados você prevê que este grupo de pessoas alcançaria?

\section{PLANO DE AULA SUGERIDO}

O plano de aula foi pensado para uma turma entre vinte a trinta alunos divididos em quatro grupos menores e tem duração prevista de três horas e meia considerando-se que a leitura individual do caso se dê em sala de aula. A partir de um encadeamento sequencial a proposta é compostas de cinco partes/momentos. $A$ primeira serve como um quebra gelo, ou seja, é destinada a ajudar o grupo a iniciar o debate bem como introduz o tema para discussão, na segunda e na terceira parte ocorrem debates entre os grupos. Já a quarta trata-se de uma dinâmica (esquete) e na última ocorre o fechamento da aula, conforme quadro 1 a seguir. 


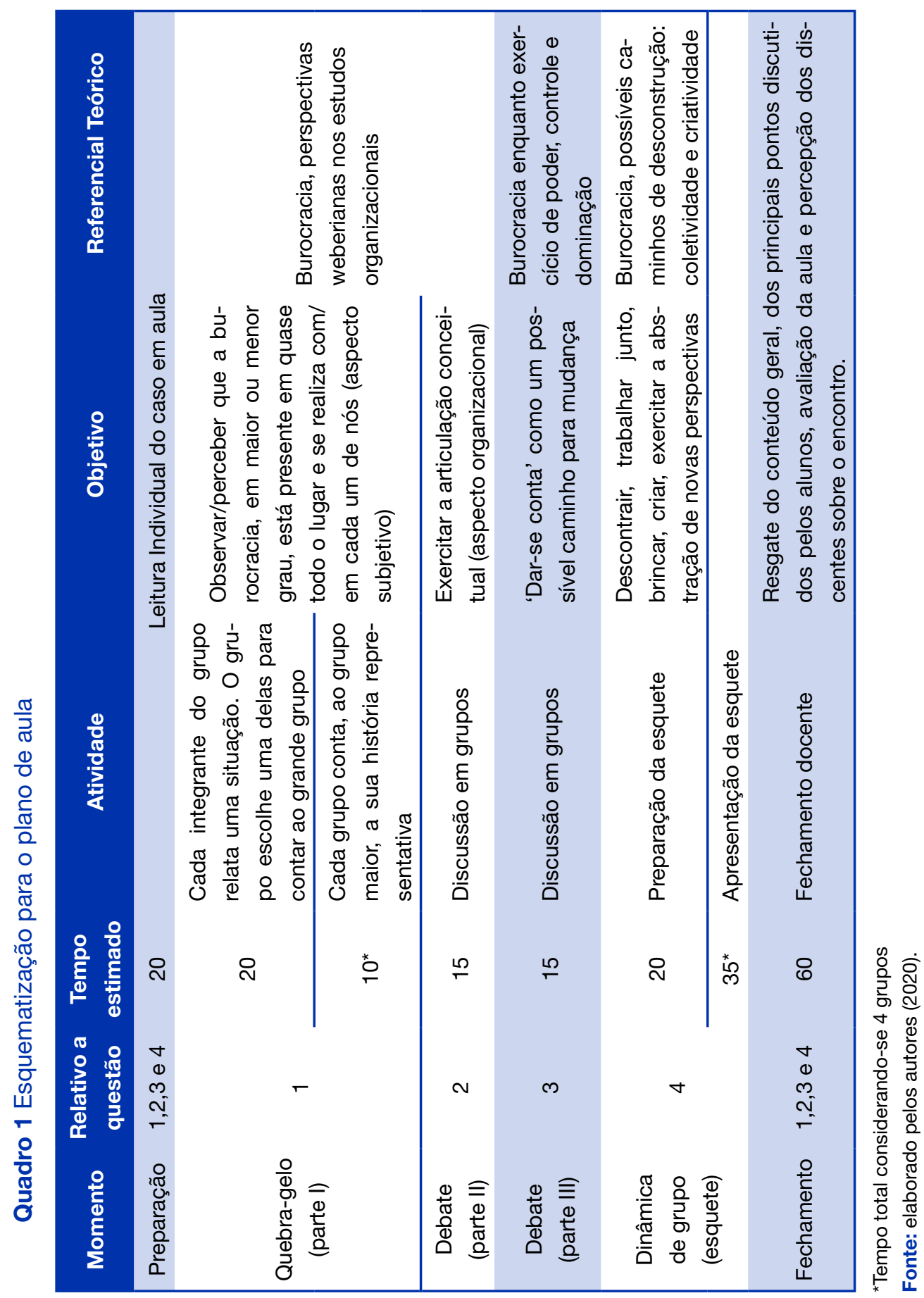


A primeira parte inicia com a pergunta de número um (1). O grande grupo é divido em quatro grupos menores de cinco alunos ou mais. Em cada um destes grupos seus integrantes contam uma história (pessoal ou de um caso conhecido por eles) em resposta à questão. Após todos os integrantes terem contato a sua história o grupo irá escolher, conjuntamente, uma (1) entre todas, como a mais representativa. Um representante de cada grupo menor irá, então, contar/compartilhar com grande grupo a 'história do grupo'. Para o primeiro momento - em que os integrantes contam cada um a sua história nos grupos menores - o tempo estimado é de vinte minutos. Para a segunda parte - onde cada grupo conta a 'história escolhida pelo grupo' ao grande grupo - o tempo total para todos os quatro grupos compartilharem a sua história é de dez minutos. O objetivo desde momento da aula é observar/perceber o aspecto subjetivo da burocracia, ou seja, que, em maior ou menor grau, ela está em quase todo o lugar e se realiza com/em cada um de nós.

A segunda parte da aula inicia com a pergunta de número dois (2). O grande grupo continua divido em grupos menores de cinco alunos ou mais que podem permanecer os mesmos ou terem seus integrantes alternados. A instrução é para que a questão seja discutida pelo grupo. O tempo estimado para esta atividade é de vinte minutos. O objetivo desde momento da aula é exercitar uma aproximação entre a situação dilema e o conceito, agora, a partir de uma perspectiva organizacional.

A terceira inicia com a pergunta de número três (3). O grande grupo continua divido em grupos menores, de cinco alunos ou mais, que podem permanecer os mesmos ou terem seus integrantes alternados. A instrução é para que a questão seja discutida pelo grupo. O tempo estimado para esta atividade é de vinte minutos. O objetivo deste momento é adentrar mais reflexivamente ao tema, em especial, relacionando-o com poder, controle e dominação e a partir disso refletir sobre a mudança e ressignificação no âmbito relacional e social.

A quarta parte, trata-se de um esquete, ou seja, uma pequena peça teatral em que os grupos vão criar e dramatizar uma situação que envolva dois tipos de emoções. Para este exercício o(a) professor(a) entregará a cada grupo uma instrução que informará onde (o lugar) um evento iniciará e onde ele terminará (ver quadro 2 a seguir) e, ainda, uma lista de emoções (ver tabela 1, na seção 'Apêndice' deste material). Os grupos irão escolher na lista de emoções uma negativa (que dará início ao ato dramático) e uma positiva (que encerrará o mesmo) e de posse disso terão 
cerca de vinte minutos para projetar/criar a esquete do grupo e aproximadamente cinco a dez minutos para se apresentarem ao grande grupo. Vamos a um exemplo elucidativo: supondo que um grupo tenha recebido a instrução ' $g$ ', a dramatização iniciaria 'em um posto de gasolina' e terminaria 'com entregador de pizza tocando na sua campainha', com isso em mãos o grupo irá escolher uma emoção negativa da lista a sua escolha (por exemplo: ansiedade, depressão, tristeza, vergonha e assim por diante) para iniciar a peça, assim como, irá escolher uma emoção positiva da lista (por exemplo: amor, amizade, altruísmo, paciência, prazer e assim por diante) para fechar a dinâmica. Parte importante desta dinâmica é que todos devem participar da encenação. Caso algum aluno não deseje participar da dramatização, ele poderá, neste caso, assumir o 'papel' na peça de um objeto ou animal da cena. O objetivo dessa dinâmica é exercitar a capacidade de percepção e transformação do vigente através de um viés lúdico que perpassa pela construção coletiva e pelo exercício da criatividade, alternativas essas que visão superar o controle e a dominação presentes nas organizações burocráticas.

A quinta e última parte dessa aula encerra o encontro a partir de um breve resgate do conteúdo pelo docente, discussão sobre o que surgiu nos grupos frente aos debates das questões um, dois e três, valendo-se, convenientemente, das proposições indicadas na próxima seção ‘alternativas de análise' e, por fim, a avaliação da aula e percepções dos discentes sobre o encontro.

\section{Quadro 2 Onde começa e onde termina a esquete}

\begin{tabular}{|cll|} 
Situação & \multicolumn{1}{c|}{ Inicia } & \multicolumn{1}{c|}{ Termina } \\
\hline a & $\begin{array}{l}\text { Na secretaria pedindo o histórico } \\
\text { escolar }\end{array}$ & $\begin{array}{l}\text { Em uma recepção de calouros } \\
\text { do curso }\end{array}$ \\
b & $\begin{array}{l}\text { Preenchendo um formulário on- } \\
\text {-line para uma vaga de emprego }\end{array}$ & $\begin{array}{l}\text { Embarcando para um estágio no } \\
\text { exterior }\end{array}$ \\
c & $\begin{array}{l}\text { Na farmácia comprando pasti- } \\
\text { Ihas para garganta }\end{array}$ & No aniversário de um(a) amigo(a) \\
d & Coffee break de um evento & Em um Airbnb na Praia do Rosa
\end{tabular}




$\begin{array}{|cll|}\text { e } & \begin{array}{l}\text { Recebendo a rejeição de um } \\ \text { artigo em uma revista }\end{array} & \begin{array}{l}\text { 'Maratonando' uma série no final } \\ \text { de semana }\end{array} \\ \text { f } & \text { No caixa do supermercado } & \begin{array}{l}\text { Sendo informado(a) sobre uma } \\ \text { menção honrosa de seu TCC }\end{array} \\ \text { g } & \text { Em um posto de gasolina } & \begin{array}{l}\text { Com o entregador de pizza } \\ \text { tocando a sua campainha }\end{array} \\ \text { h } & \text { Em uma reunião no escritório } & \text { Recebendo um presente } \\ \text { i } & \begin{array}{l}\text { Ligando para a operadora do seu } \\ \text { celular }\end{array} & \text { Em um almoço de família } \\ \text { j } & \begin{array}{l}\text { Preparando uma apresentação } \\ \text { para aula }\end{array} & \text { Em um camping selvagem } \\ \text { k } & \begin{array}{l}\text { Encaixotando suas coisas para } \\ \text { uma mudança }\end{array} & \text { Piquenique no parque com } \\ \end{array}$

Fonte: Elaborado pelos autores (2020).

\section{ALTERNATIVAS PARA ANÁLISE COM BASE NAS PERSPECTIVAS TEÓRICAS QUE FUNDAMENTAM O CASO}

Do ponto de vista meramente descritivo, administrar é planejar, organizar, coordenar, comandar e controlar, "entretanto, nem sempre se atenta para o fato de que se administrar é planejar, organizar, coordenar, comandar e controlar [e] ser administrado significa ser planejado, organizado, comandado e controlado", logo a administração possui também um significado político frequentemente negligenciado, ou seja, o fato de que administrar é exercer um poder delegado e, por assim sê-lo, permite direcionar o comportamento do outro ou dos outros; "há muitas formas de se exercer poder. Pode-se impor, pode-se coagir pode-se corromper, pode-se persuadir, pode-se seduzir, pode-se manipular. Em muitas situações todas essas possibilidades podem entrar no jogo do poder e nem sempre é fácil discernir uma modalidade da outra" (MOTTA, 2003, p. 369, grifos nossos). É por isso que entendemos este caso enquanto uma forma de ensinar e refletir sobre a prática administrativa e de gestão, olhando-se para um dos elementos que mais Ihe relacionam com poder e controle, ou seja, o conceito de burocracia. A seguir apresentamos possibilidades de articulação das questões disparadoras capazes 
de apontar caminhos para a articulação do debate e formulação de respostas as situações dilema.

\section{Questão 1 e 2 - o que é burocracia, perspectivas weberianas nos estudos or- ganizacionais.}

O conceito de burocracia tem sido debatido em diversas áreas do conhecimento, mas é inegável que a grande contribuição sobre o tema tenha sido feita por Max Weber, base para vários outros pesquisadores de diversas correntes epistemológicas (DE FARIA; MENEGHETTI, 2011). Weber (2015) observa, especialmente, o processo de racionalização da sociedade na passagem da Idade Média para a Idade Moderna. Situação em que as transformações de um mundo social baseado no cálculo utilitário de consequências dá lugar a uma racionalidade instrumental-legal que se institui e altera as relações na sociedade, fazendo com que a burocracia moderna se consolide. Fruto de um processo que tem, na sua essência, a finalidade de concentrar os meios materiais de administração nas mãos das elites detentoras do capital, mediante o desenvolvimento das grandes empresas capitalistas (WEBER, 2015). Conforme esse autor, a burocracia moderna possui características centrais, quais sejam: está sob regência de áreas de jurisdição fixas e oficiais, ordenadas por leis e normas administrativas; estabelece uma relação de autoridade, delimitada por normas relativas aos meios de coerção e de consenso; cria uma relação hierárquica, definindo postos e níveis de autoridades, além de um sistema de mando e subordinação com gerência das atividades e tarefas delegadas por autoridade; com ela a administração é formalizada por meio de documentos, que acabam por regular a conduta e as atividades das pessoas; em uma administração burocrática especializada, pressupõe-se treinamento especializado; as atividades e tarefas de um trabalho, que podem ser apreendidas por qualquer trabalhador sevem ser descritas e delimitadas pela criação de cargos mais ou menos estáveis; a ocupação de um cargo configura uma profissão de ordem impessoal e transitória e, ainda, o treinamento especializado volta-se para generalizar o cargo e transformá-lo em profissão. Sinteticamente, para Weber (2015) a burocracia exprime o tipo mais puro de dominação racional-legal. Neste tipo o dirigente/governante, possui sua posição de autoridade em virtude de designação ou eleição. Ela ocorre tanto no Estado como em uma empresa privada, numa associação com fins utilitários ou 
mesmo numa união de qualquer natureza que disponha de um quadro administrativo hierarquicamente articulado.

Ademais, o conceito de burocracia pode ser considerado como um pressuposto elementar para a existência da teoria das organizações, visto que é a partir da burocracia enquanto forma de racionalização que as organizações complexas modernas se efetivaram como objetos de análise. Neste sentido, conforme De Faria e Meneghetti (2011), na discussão sobre o tema no campo da análise das organizações, especialmente nos estudos críticos da área, destacam principalmente dois autores: Mauricio Tragtenberg e Fernando Cláudio Prestes Motta. Para Tragtenberg, autor notadamente avesso a qualquer forma de burocratização que impedisse a autonomia dos indivíduos, considera o processo de burocratização um fenômeno social em que o próprio pensamento da atualidade encontra-se refém (DE FARIA; MENEGHETTI, 2011). Em Tragtenberg, esclarecem ainda De Faria e Meneghetti (2011) a burocracia materializa a face mais perversa do capital, de modo que em seus estudos o autor mostra-se claramente preocupado em criar mecanismos de defesa ante aos seus efeitos. Isso significa que ao refletir sobre o aspecto da impessoalidade, por exemplo, entende que a mesma se transforma em álibi das eventuais injustiças; além disso, quando os meios estão adequados irrestritamente para os fins, as pessoas são, invariavelmente, identificadas como os fatores centrais de insucessos em um claro descolamento de uma análise mais ampla, organizacional. Já Prestes Motta (2017, p. 7) afirma que a "burocracia é uma estrutura social na qual a direção das atividades coletivas fica a cargo de um aparelho impessoal hierarquicamente organizado, que deve agir segundo critérios impessoais e métodos racionais". O autor entende a burocracia de três formas: como poder, como controle e como alienação de modo que a entende como um instrumento da classe dominante que impõe sua ascendência sobre as demais classes, sendo que o "modo burocrático de pensar leva o homem ao vazio e à luta por pequenas posições na hierarquia social de prestígio e consumo" (PRESTES MOTTA, 2017, p. 13). Tal dominação é feita pelas organizações (empresas, escola, partidos, sindicatos e outros) e pelo Estado, por meio do estabelecimento de um modo de vida específico, de acordo com os interesses do capital (DE FARIA; MENEGHETTI, 2011). A hierarquia exerce significativo na burocracia como controle, estabelecendo uma relação de vigilância e de disciplinamento essencial para garantir a submissão. Particularmente interes- 
sante a percepção do autor que entende que o papel das organizações burocráticas não está associado apenas à produção de bens, capital, serviços, tampouco, à (re)produção da mão-de-obra como força de trabalho ou garantia da sobrevivência do trabalhador por meio do salário, mas sim garantir o controle social por meio do estabelecimento das relações de poder que sempre ocorrem entre desiguais (PRESTES MOTTA, 2017).

\section{Questão 3 - burocracia enquanto exercício de controle, poder e dominação.}

Dominação, na teoria weberiana é a disposição inculcada, internalizada, interiorizada, ou ainda, uma obediência acrítica e sem resistência, reconhecida como válida pelas pessoas sobre as quais ela se exerce; na sessão "A vigência da legitimidade" em sua obra Economia e Sociedade, Weber (2015, p. 170) iguala o termo à autoridade quando escreve "em cada caso individual a dominação ("autoridade") pode basear-se nos mais diversos motivos de submissão: desde hábito inconsciente até considerações puramente racionais, referente a fins". De modo que os dominados precisam acreditar que as ações que mantêm com os dominantes são legítimas, têm justificativa e que essa justificativa é cabível e aceitável. É este tipo de dimensão simbólica que não permite que se confunda dominação com poder, conceitos ligados, mas ainda sim distintos, visto que a legitimidade aparece como um componente intrínseco na primeira. Isto significa dizer que a dominação - enquanto um estado das coisas em que a(s) pessoa(s) que impõe(m) sua vontade sobre outra(s) pessoa(s) acredita ter(em) direito de fazê-lo, bem como o governado acredita que é seu dever obedecer - precisa que existam princípios e crenças que a tornem legítima tanto aos olhos daquele que manda quanto aos do que obedece (WEBER, 2015). Os princípios e as crenças tornam a dominação legítima lhe garantem estabilidade. Conforme a maneira como eles são legitimados, Weber (2015) elencou três tipos de dominação: a racional-legal, a tradicional e a carismática. $A$ tradicional se respalda na tradição e na crença na legitimidade do soberano, nela o que sempre existiu é o valido, q carismática é aquela em que não há a concepção de uma alçada hierárquica ou de competência, ou seja, no lugar de um quadro administrativo, existe a ideia de discípulos, de seguidores, os homens de confiança. Já a dominação legal ou racional-legal se baseia na legalidade definida por normas e estatutos jurídicos objetivos. A burocracia exprime o tipo mais puro de dominação 
racional-legal. Neste tipo o dirigente/governante, possui sua posição de autoridade em virtude de designação ou eleição.

No que tange ao poder, pode-se discuti-lo com os alunos a questão da própria organização como uma forma de poder e que, no caso deste estudo, se manifestaria, em especial, enquanto 'poder disciplinar' (MOTTA, 2017, p. 35). Sendo que o poder disciplinar pode ser encontrado em outras instituições, "geralmente aquelas que se organizam em locais fechados e com estruturas burocráticas rígidas, como a fábrica, o manicômio, o convento" (MOTTA, 2017, p. 36). Para Motta (2017) o poder disciplinar é um aspecto essencial de qualquer organização formal no capitalismo burocrático sua lógica é social - antes de ser organizacional - pois seu objetivo é a produção de corpos dóceis cujo potencial produtivo é liberado e o potencial político inibido. Pertinente ainda discutir com os alunos que este tipo de poder (disciplinar) não ‘é algo do passado' e que não está presente nas empresas modernas. Max Pagès (1987), por exemplo, desenvolveu sua pesquisa junto a uma grande corporação multinacional. Sua constatação foi de que o caráter sutil do poder disciplinar, na grande empresa moderna, se dá através de uma identificação afetiva e intelectual dos indivíduos com a organização. Isso significa pensar um poder disciplinar agindo sobre "o sistema pulsional dos indivíduos, que passam a promover ativamente seus objetivos e políticas" da empresa, ou seja ocorre a introjeção/assimilação pelos indivíduos das exigências fixadas pela organização (MOTTA, 2017, p. 37). As organizações conseguem, através desse processo, canalizar ao máximo a energia dos indivíduos em seu benefício, sem precisar empregar um sistema de punições funcionando com base na repressão. Neste formato de poder disciplinar o sujeito, submetendo-se totalmente, trabalha para a organização como se fosse para si próprio; ele experimenta o sentimento de que a organização faz parte dele. Há, portanto, uma tomada do indivíduo pela organização a nível do inconsciente; essa tomada é especialmente forte porque é paralela a uma dissolução da instância crítica. Aqui o indivíduo não tem medo de ser punido se não for bem-sucedido; ser bem-sucedido torna-se uma necessidade vital para ele (PAGÈS, 1987). A burocracia, pode, portanto, ser discutida ainda como um sistema de dominação baseado na reprodução da dominação da natureza - inclusive do homem em relação ao próprio homem (controle sobre os corpos, controle sobre as necessidades básicas, controle sobre se pode ou não "ir ao banheiro"). Como colocam De 
Faria e Meneghetti, (2011, p. 438) "a burocracia é capaz de criar costumes, normas informais, ideias e imaginários, tornando-se responsável pelo controle intersubjetivo" de modo que a submissão, os comportamentos padrão e o disciplinamento não são decorrentes "apenas da forma objetiva" como a burocracia se institui na organização. Uma discussão neste sentido amplia o debate observando que a burocracia investe também no controle intersubjetivo, e esse movimento é essencial para que o controle possa ser efetivo, como colegas se opondo quando o professor transfere a liberdade de escolha de ir ou não ao banheiro aos alunos ou ainda a situação do aluno 'dedurando' os colegas.

\section{Questão 4 - possíveis caminhos: coletividade e criatividade}

Espera-se que os alunos consigam caminhar para soluções tanto individuais quanto coletivas. No que tange as ações coletivas o texto revela de forma sutil que a união de forças entre os alunos e um grupo de pais conseguiu invalidar a diretriz sobre a questão do controle e acesso ao banheiro repassando aos alunos a liberdade e a responsabilidade por tal deliberação. Neste sentido, Motta (2003, p. 6), referindo-se ao ensino universitário, mas que cabe ao caso de ensino em questão, vai colocar que "a alternativa é a criação de canais de participação real de professores, estudantes e funcionários no meio universitário, que oponham-se à esclerose burocrática da instituição", Segundo este autor, a participação (do executivo, do operário, do professor, do estudante e etc) não é um remédio mágico aos males da burocracia que nos cerca, porém a experiência demonstra, que no caso de uma organização de ensino, como a que aqui retratamos, a simples presença do discente em colegiados já é um "fator de sua moralização" (MOTTA, 2003, p. 6). Isso significa refletir que, ações coletivas e individuais, em certa medida, se conectam. Neste sentido - quanto as ações individuais - , Motta (2017) nos remete à questão da criatividade como uma possível ponte de superação das dicotomias inerentes ao controle e a dominação. Segundo o autor, a criatividade surge como um elemento que favoreceria o processo de aceitação, por parte do indivíduo das normas essenciais para a organização ao mesmo tempo que o lhe instrumentaria para fazer frente a rejeição daquilo que é apenas relevante em um sentido periférico e que impactaria as relações entre os sujeitos de forma negativa. O indivíduo orientado nesses termos consegue com frequência exercer influência 
sobre a coletividade organizacional o que, alerta, já significa muito, porque o relacionamento indivíduo-organização é um relacionamento entre desiguais (MOTTA, 2017). Nosso personagem principal, como se vê, conseguiu faze-lo, mesmo que isso tenha ocorrido depois de sua saída. Seguindo por essa linha de pensamento a sugestão aqui é trabalhar a superação por meio de seu oposto. Isso significa pensar que diante do normativo, formalismo da fixidez da burocracia, a criatividade pode ser entendida como um caminho 'criativo' de desvio. O que modifica a dureza do controle e da repressão, inerentes a burocracia pode ser, neste sentido, aquilo que remete a utopia, ou seja, sobre sonho, sobre a invenção, a fantasia de um outro lugar, outra situação, outra possibilidade dentro de uma mesma situação tal como um exercício de deslocamento para uma outra possibilidade de olhar. Uma interessante tirinha do personagem Calvin (ver figura 2 a seguir) faz indiretamente uma referência justamente a este tipo de deslocamento quando o menino foge da sala de aula, dizendo ir ao bebedouro, e cria um mundo de fantasia e desafios dentro de seu próprio armário - em proximidade com este caso e com o conteúdo discutido neste momento final. Tal tirinha pode ser projetada aos alunos, ao final da aula, junto com estas observações, reforçando o conteúdo latente (criatividade) e o propósito (deslocamento para exercitar novos olhares) da dinâmica do exercício de esquete que realizaram. Em essência, esta dinâmica traz a proposta de uma integração de paradigmas e não sua exclusão, tal como uma estratégia integracionista. Mesmo que a hegemonia do paradigma funcionalista no campo da Administração seja axiomática (PAULA, 2016) entende-se que um caminho de possibilidade passe por uma abordagem que enfatize questões subjetivas que, neste exercício final, são representadas pelo lúdico, pela construção coletiva e pelo exercício de uma criatividade reflexiva seguindo-se, desta forma, por propostas de ensino e aprendizagem voltadas a uma perspectiva de autonomia e emancipação dos sujeitos (CANOPF, 2018). 
Figura 2 Stupendousman, criatividade enquanto elemento de deslocamento para novos olhares
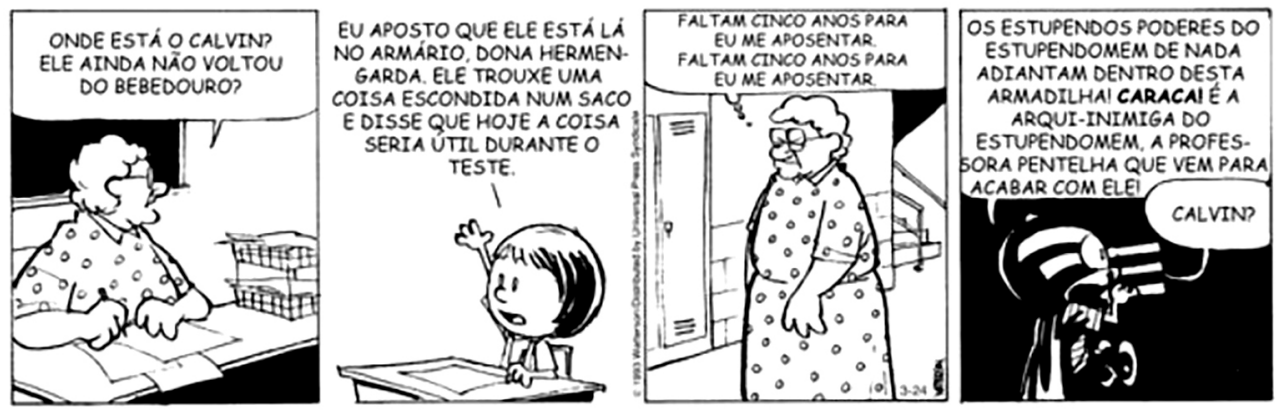

Fonte: Pinterest (2020)

O foco central deste caso de ensino é o debate da teoria clássica da burocracia, como forma de introdução do tema dentro dos estudos organizacionais. Ainda assim, parece conveniente algumas proposições finais, mesmo que sucinta, sobre o que a literatura atual aponta como caminhos de superação. Para tanto, tomaremos quatro perspectivas em particular: da divisão das tarefas, da alocação de tarefas, dos sistemas de reconhecimento e recompensa e ainda em relação ao fornecimento de informações. No que tange a administração das tarefas, em uma burocracia engessada, o gerenciamento de nível superior fornece a arquitetura das tarefas. Para que se possa controlar todo o processo, a operação é dividida em áreas jurisdicionais oficiais fixas. Os gerentes de cada uma dessas áreas dividem a tarefa em subtarefas menores, tornando a divisão de tarefas um processo de cima para baixo. Em sistemas menos burocráticos as equipes teriam autonomia para estabelecer as submetas e tarefas necessárias para atingir a meta geral da equipe. Por exemplo, determinada equipe de consultoria que trabalha com um cliente específico pode deparar-se com um desafio único que exigirá uma solução criativa e não usual e, neste caso, o grupo teria autoridade para decidir a melhor forma de enfrentar esse desafio (MARTELA, 2019). No que se refere a alocação das tarefas, em uma burocracia clássica, a alocação de tarefas também é feita de cima para baixo. Tendo estabelecido as tarefas mais amplas necessárias para o cumprimento das metas organizacionais, a alta administração as aloca para o próximo nível de administração, que por sua vez toma as decisões de alocação em relação aos seus 
subordinados. Assim, cada gerente é responsável por fazer a alocação de tarefas para a camada de funcionários diretamente abaixo deles. Em sistemas menos burocráticos as equipes normalmente têm autoridade para dividir as tarefas entre si como desejarem, criando assim bolsões de poder de decisão (inevitavelmente inerentes ao processo organizacional como um todo) mais distribuídos e menos desiguais (MARTELA, 2019). Em engendramentos deste tipo equipes tendem a se formar espontaneamente em torno de tópicos de interesse de modo que um processo de governança informal permite que qualquer pessoa, mesmo os membros mais jovens, proponha mudanças nas funções, responsabilidades, políticas e direitos de decisão em seu grupo de trabalho (BURTON et. al, 2017). Em relação aos sistemas de reconhecimento/recompensa, em uma burocracia tradicional, normalmente não há pressuposto de que as tarefas seriam intrinsecamente recompensadoras, visto que a alienação do trabalho é vista como um dos efeitos colaterais infelizes de maior racionalização e eficiência. Consequentemente, a compensação na forma de salários e bônus é o principal mecanismo de recompensa. Também em sistemas menos burocráticos, a compensação monetária é o principal mecanismo de recompensa, no entanto, dada a estrutura mais aberta, interativa e dinâmica as pessoas podem ser motivadas pela capacidade de trabalhar em projetos mais interessantes de forma mais criativa. Sob esta ótica, em organizações menos burocráticas se encontraria o pressuposto de que as pessoas não são passivas e preguiçosas, mas muito ao contrário disso, que são ativas e dispostas a ter um bom desempenho se lhes for dada uma tarefa que consideram intrinsecamente motivadora (DECl; OLAFSEN; RYAN, 2017). Por fim, sob o fornecimento de informações, tem-se que nas estruturas burocráticas os limites das de tarefas, à medida que organizados de forma rígida e com instruções precisas, limitam a distribuição de informações abrangentes e por sua vez, em organizações menos burocráticas a transparência de todas as informações importantes e distribuição ativa de informações surge para garantir a capacidade de cada funcionário de tomar decisões que beneficiem a totalidade (LEE; EDMONDSON, 2017).

\section{FONTES PRINCIPAIS PARA ABORDAGEM DO CASO}

O quadro 3, apresentado na sequência, apresenta uma relação de referências complementares que podem auxiliar docentes na construção teórica deste caso 
de ensino. A referência é seguida de uma breve nota explicativa sobre o motivo da indicação.

Quadro 3 Indicação de fontes principais para abordagem do caso

\begin{tabular}{|c|c|c|c|}
\hline Título & Motivo da sugestão & Referência & Área \\
\hline $\begin{array}{l}\text { O que é } \\
\text { burocracia }\end{array}$ & $\begin{array}{l}\text { Nesta pequena, mas elucidativa } \\
\text { obra, são abordadas questões } \\
\text { basilares tais como: qual o signi- } \\
\text { ficado da burocracia? A quem ela } \\
\text { serve? A burocracia é abordada } \\
\text { a partir de várias perspectivas } \\
\text { entre elas, poder, dominação e } \\
\text { alienação }\end{array}$ & $\begin{array}{l}\text { MOTTA, F. C. P. O que é } \\
\text { burocracia. São Paulo: } \\
\text { Brasiliense, } 2017 .\end{array}$ & $\begin{array}{l}\text { Estudos } \\
\text { Organiza- } \\
\text { cionais }\end{array}$ \\
\hline $\begin{array}{l}\text { Economia e } \\
\text { sociedade }\end{array}$ & $\begin{array}{l}\text { Umas das obras mais importantes } \\
\text { do arcabouço teórico weberiano }\end{array}$ & $\begin{array}{l}\text { WEBER, M. Economia e } \\
\text { Sociedade (volumes } 1 \text { e } \\
\text { 2). Brasília: UnB, } 2015 .\end{array}$ & $\begin{array}{l}\text { Sociologia, } \\
\text { Estudos } \\
\text { Organiza- } \\
\text { cionais }\end{array}$ \\
\hline $\begin{array}{l}\text { Burocracia } \\
\text { como or- } \\
\text { ganização, } \\
\text { poder e } \\
\text { controle }\end{array}$ & $\begin{array}{l}\text { Artigo que analisa a forma como } \\
\text { Maurício Tragtenberg e Fernando } \\
\text { C. Prestes Motta, dois impor- } \\
\text { tantes autores de Estudos Orga- } \\
\text { nizacionais abordam o tema da } \\
\text { burocracia }\end{array}$ & $\begin{array}{l}\text { DE FARIA, J. H.; } \\
\text { MENEGHETTI, F. K. } \\
\text { Burocracia como or- } \\
\text { ganização, poder e } \\
\text { controle. RAE-Revista } \\
\text { de Administração de } \\
\text { Empresas, v. 51, n. 5, p. } \\
\text { 424-439, jan./fev. } 2011 . \\
\text { DOI: 10.1590/S0034- } \\
\text { 75902011000500002 }\end{array}$ & $\begin{array}{l}\text { Estudos } \\
\text { Organiza- } \\
\text { cionais }\end{array}$ \\
\hline
\end{tabular}

Fonte: Elaborado pelos autores (2020). 


\section{Apêndice}

Em seguida, na tabela 1 disponibilizamos a 'lista das emoções' para realização do esquete envolvendo a análise do caso.

Tabela 1 Lista das emoções

\section{Lista das emoções}

\begin{tabular}{|c|c|c|c|}
\hline Agressividade & Coragem & Pânico & Piedade \\
\hline Afetividade & Culpa & Pena & Possessividade \\
\hline Aflição & Curiosidade & Histeria & Prazer \\
\hline Alegria & Contentamento & Hostilidade & Preguiça \\
\hline Altruísmo & Criatividade & Humor & Preocupação \\
\hline Ambivalência & Depressão & Humildade & $\mathrm{Paz}$ \\
\hline Amizade & Desabafo & Humilhação & Raiva \\
\hline Amor & Deslumbramento & Inspiração & Remorso \\
\hline Angústia & Desprezo & Interesse & Repugnância \\
\hline Ansiedade & Dó & Indecisão & Resignação \\
\hline Antipatia & Decepção & Inveja & Ressentimento \\
\hline Antecipação & Dúvida & Ira & Saudade \\
\hline Apatia & Desapontamento & Isolamento & Simpatia \\
\hline Arrependimento & Egoísmo & Intriga & Soberba \\
\hline Arrogância & Empatia & Luxúria & Sofrimento \\
\hline Autopiedade & Esperança & Mágoa & Solidão \\
\hline Avareza & Euforia & Mau-humor & Surpresa \\
\hline Bondade & Entusiasmo & Medo & Susto \\
\hline Bem aventurança & Epifania & Melancolia & Tranquilidade \\
\hline Benevolência & Excitação & Mazela & Tédio \\
\hline Carinho & Fanatismo & Nojo & Timidez \\
\hline Cobiça & Felicidade & Nostalgia & Tristeza \\
\hline Compaixão & Frieza & Ódio & Vaidade \\
\hline Confusão & Frustração & Orgulho & Veracidade \\
\hline Ciúme & Gratificação & Paixão & Vergonha \\
\hline Constrangimento & Gratidão & Paciência & Vingança \\
\hline
\end{tabular}

Fonte: Adaptado de Sabercoletivo (2020) 


\section{Agradecimentos}

Nossos agradecimentos à professora Lisiane Closs pelos aprendizados oportunizados através da disciplina ‘Ensino-Aprendizagem em Administração', do Programa de Pós-Graduação em Administração da Universidade Federal do Rio Grande do Sul (UFRGS), os quais serviram de inspiração à construção desse material. Nosso agradecimento, também, ao entrevistado que gentil e atenciosamente contribuiu com sua história para elaboração deste caso de ensino, mostrando que "contribuir socialmente" é possível de inúmeras formas.

Agradecemos ainda pela oportunidade da Bolsa sanduíche (Greice Martins Gomes) e do Pós-Doutoramento (Ney Bruck) realizados na Universidade de Coimbra (PT), em especial ao Professor Dr. Luciano Lourenço, pela origem de muitas concepções deste trabalho.

\section{Referências}

BURTON, R. M. et al. GitHub: exploring the space between boss-less and hierarchical forms of organizing. Journal of Organization Design, v. 6, n. 1, p. 1-19, apr./may. 2017. DOI: 10.1186/s41469-017-0020-3 CANOPF, L. et al. Prática docente no ensino de administração: analisando a mediação da emoção. Organizações \& Sociedade, v. 25, n. 9, p. 371-391, jul./set. 2018. DOI: 10.1590/1984-9250862

DE FARIA, J. H.; MENEGHETTI, F. K. Burocracia como organização, poder e controle. RAE-Revista de Administração de Empresas, v. 51, n. 5, p. 424-439, jan./fev. 2011. DOI: 10.1590/S003475902011000500002

DECI, E. L.; OLAFSEN, A. H.; RYAN, R. M. Self-determination theory in work organizations: The state of a science. Annual Review of Organizational Psychology and Organizational Behavior, v. 4, n. 5, p. 19-43, jan./feb. 2017. DOI: 10.1146/annurev-orgpsych-032516-113108

LEE, M. Y.; EDMONDSON, A. C. Self-managing organizations: Exploring the limits of less-hierarchical organizing. Research in organizational behavior, v. 37, n. 7, p. 35-58, nov./dec. 2017. DOI: 10.1016/ j.riob.2017.10.002

MARTELA, F. What makes self-managing organizations novel? Comparing how Weberian bureaucracy, Mintzberg's adhocracy, and self-organizing solve six fundamental problems of organizing. Journal of Organization Design, v. 8, n. 1, p. 23, nov./dec. 2019. DOI: 10.1186/s41469-019-0062-9

MINAYO, M. C. (org). Pesquisa Social: Teoria, Método e Criatividade. Petrópolis: Vozes, 2016.

MOTTA, F. C. P. Administração e participação: reflexões para a educação. Educação e pesquisa, v. 29, n. 2, p. 369-373, jul./dez. 2003. 
MOTTA, F. C. P. O que é burocracia. São Paulo: Brasiliense, 2017.

PAGĖS, M. et. al. O poder das organizações: a dominação das multinacionais sobre os indivíduos. São Paulo: Atlas, 1987.

PAULA, A. P. P. de. Beyond paradigms in Organization Studies: the Circle of Epistemic Matrices. Cadernos EBAPE.BR, Rio de Janeiro, v. 14, n. 1, p. 24-46, jan./mar. 2016. DOI: 10.1590/1679-395131419 PINTEREST. Pinterest, 2020. Figura 1 - A Mafalda e a 'sua' Burocracia. Disponível em: < https://i.pinimg. com/originals/73/c9/e0/73c9e01c90e23f132c1d1ebfdc38518e.jpg> acesso em 29 de set. 2020.

PINTEREST. Pinterest, 2020. Figura 2 - Stupendousman, criatividade enquanto elemento de deslocamento para novos olhares. Disponível em: < https://i.pinimg.com/originals/fe/cc/d9/feccd955f99cefc999466beb8de18bad.jpg > acesso em 29 de set. 2020.

SABER COLETIVO. EduCarreira, 2019. Tabela 1 - Lista das emoções. Disponível em: Disponível em <https://educarreira.com.br/wp-content/uploads/2019/11/Lista-de-Emo\%C3\%A7\%C3\%B5es.pdf> acesso em 20 de dez. 2020.

WEBER, M. Economia e Sociedade. Brasília: UnB, 2015. 